\title{
Rural Road Extraction using Object Based Image Analysis (OBIA): A case study from Assam, India
}

\author{
Ankita Medhi and Ashis Kumar Saha \\ Department of Geography, Delhi School of Economics, University of Delhi, ankita.medhi@gmail.com, ashisksaha@gmail.com
}

\begin{abstract}
Rural roads in India have been considered as significant component for overall rural development. In India, the status of rural road connectivity is not up to the mark in some of the states. For providing better connectivity in the rural areas the information on roads are considered important. Detailed mapping of the roads can be useful for planning further road connectivity and proving access to facilities in the rural areas. For detailed mapping of roads higher resolution satellite imageries are required. Object based Image Analysis (OBIA) has emerged as a promising map analysis approach using high and very high resolution imageries. Feature extraction is one of the important aspect in OBIA extracting features such as roads, buildings, water bodies and other important features of interest from the high resolution imageries. In the present study, an attempt has been made to extract rural roads of Titabor in Jorhat district of Assam (India). Various OBIA based extraction methods have been used for extracting roads using high \& very high resolution Resourcesat-II $(5.8 \mathrm{~m})$ and Kompsat imagery (2.8m MS \& $0.7 \mathrm{~m}$ PAN). The results have been compared and relative advantages were evaluated.
\end{abstract}

Keywords: Rural Road, Object Based Image Analysis (OBIA), Road Extraction, Multiresolution segmentation

\section{Introduction}

Rural roads are considered to be very important in developing countries like India where about 70 per cent population resides in rural areas. Though many of the states have better overall rural road length, the surfaced rural road length is less in many states. Pradhan Mantri Gram Sadak Yojna (PMGSY) inducted in 2000 is the rural road flagship programme in India, which aims at 100 per cent connectivity by all-weather road. All weather roads should be negotiable in all weathers, however, this does not necessarily imply that it should be paved or sealed or blacktopped (MoRD 2005). Most of the rural roads in the developing countries are unpaved, earthen or gravel roads (Rao 2000). The unpaved roads become inaccessible during rainy season and people struggle commute to other places (Fukubayashi and Makoto 2014). Paved or surfaced roads are more beneficial to the commuters than the unsurfaced roads. Therefore, all-weather roads are essential especially in rural areas for accessing the required day to day activities and facilities.

Mapping and collection of detailed information are essential for a micro area road planning and analysis. High and very high resolution satellite imageries are beneficial for extracting detailed information about any area. Feature extraction from satellite imageries such as roads, water bodies, vegetation and other curvilinear structures have been carried out using different techniques (Wang and Zhang, 2000; Bong et al. 2009; Luo et al. 2010; Mangala and Bhirud, 2010; Duong,
2012). Digital road information database is essential in many applications such as transportation planning, traffic management, navigation systems, location based services, real time travel information (Liu et al. 2003). Road extraction from remote sensing imageries has been a long term topic of research and still a challenging topic because of its complexity (Movaghati et al. 2010; Liu et al. 2003). High resolution imageries have provided a base for demand of extraction of road networks which had led to much attention (Quackenbush, 2004). The research on road extraction is of great significance for road mapping and monitoring, city planning, map updating, traffic management, GPS navigation (Shi et al., 2014). Automated road extraction technique from high to very high resolution satellite database has been recently carried out by many authors (Benz et al. 2004; Wang et al. 2006; Blaschke, 2010). Traditional pixel based classification technique fails to extract roads efficiently from the images as it uses only spectral properties of pixels. The road may be misinterpreted with similar spectral features like water, open lands etc. The same may be differentiated if the contextual information can also be used with spectral properties. Therefore, an OBIA approach recently been developed (Blaschke, 2010; Blaschke, 2014). Object based Image Analysis (OBIA) approach is an advanced image analysis technique which segments image into meaningful objects. This approach not only uses spectral characteristics but also spatial characteristics (geometry properties and texture properties) to segment the pixels into meaningful objects (Hay et al., 2003; Benz et al., 2004; Blaschke et al., 2004; Liu et al., 2003; Navulur, 2007). OBIA approach starts 
with the segmentation which segments the objects of homogeneity (Hay and Castilla, 2008; Lang, 2008) followed by assigning objects to respective classes based on sampling or rule-based approaches. To extract the roads in a typical rural area Titabor Revenue Circle in Jorhat district of Assam, India has been taken as study area. Object Based Image Analysis (OBIA) approach has been used for extracting rural roads from high resolution satellite data. The rural road extraction using OBIA approach may be used as base for mapping and helpful for further planning for rural planners.

\section{Study Area:}

Jorhat (Figure 1) is one of the districts in upper Assam located in the eastern parts of the state. Jorhat extends between $26^{\circ} 5^{\prime}-27^{0} 5^{\prime} \mathrm{N}$ latitudes and $93^{\circ}-94^{0} 5^{\prime} \mathrm{E}$ longitudes. It is bounded by Lakhimpur district on the north, Nagaland state on the south, Sivasagar district on the east and Golaghat district on the west. The river Brahmaputra forms the largest riverine island of the world i.e. Majuli island in the north of Jorhat district. According to census data (GOI, 2011) Jorhat has a population of 1,092,256 persons out of which 556,805 are male and 535,451are females. The rural population and urban population of the district are 871,722 and 220,534 respectively. Density of Population in Jorhat is 383 persons per sq.km.

There are three sub-divisions in Jorhat district for of administrative purposes viz. Jorhat, Majuli and Titabor. Each sub-division of Jorhat is divided into revenue circles and these revenue circles are divided into mauzas of several consisting villages. There are six revenue circles in the district viz. Jorhat East, Jorhat West, Titabar, Teok, Mariani and Majuli. Jorhat district consists of 11 towns which include four Statutory Towns and seven Census Towns (GOI, 2011). Jorhat district covers an area of around 2851 sq.km. where 2758.82 sq. km is rural and 92.18 sq. $\mathrm{km}$. is urban.

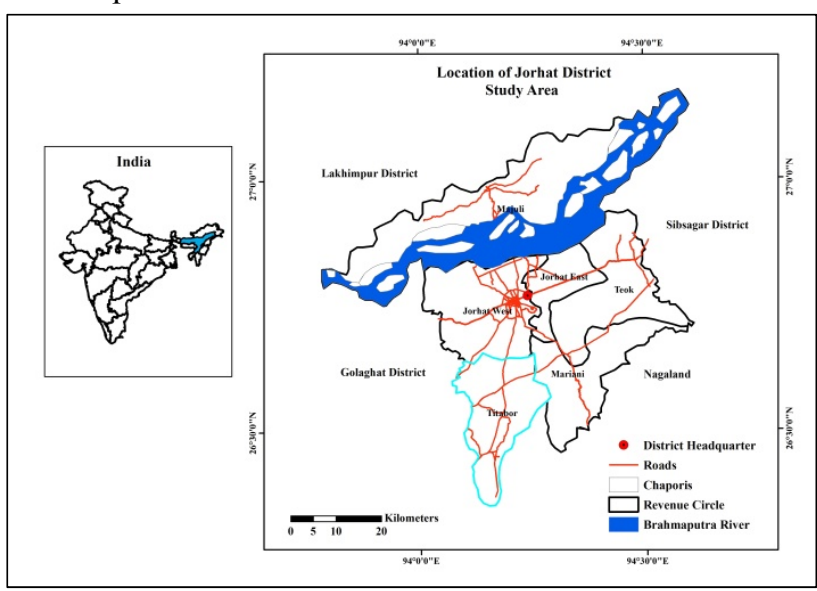

Figure 1. Study Area

For road extraction in rural areas Titabor Revenue Circle has been selected as it has the highest number of villages with all-weather roads in the district. Out of 215 villages 201 villages are connected with all-weather road. Titabor also has State Highway and Major District Road. As the area includes different categories of roads the area has been selected for road extraction. Titabor Revenue Circle recorded the highest with 57,859 persons with 24,209 males and 33,650 females. The literacy rate in this revenue circle is $80.5 \%$, males percentage is $86.2 \%$ and females $74.58 \%$.

\section{Data and Methodology:}

In this study, road extraction process has been carried out using satellite imageries of different resolutions such as IRS Resourcesat II (5.8m MS) and Kompsat 3 (2.8m MS and $0.7 \mathrm{~m}$ PAN) considering availability and cost effectiveness.

The road extraction in OBIA framework has been done using two techniques (A) Nearest Neighbour Sampling and (B) Rule based method. The major reason for choosing both these techniques is to assess the strength of these techniques and extracting road features for further planning.

The OBIA process starts with image pre-processing (viz. geo-referencing, radiometric correction etc.) followed by segmentation process which groups the image pixels into homogeneous and meaningful objects as discussed in the previous section. Further, these objects are classified into different classes using appropriate classification algorithm followed by refinement of the classes.

\subsection{Road extraction using OBIA Nearest Neighbour Approach}

The IRS-Resourcesat-II (5.8m) and Kompsat 3 (2.8m) imagery data have been used to extract road in this method. The methodology shown in Figure 2 has been used for both the imageries. To efficiently utilize computational power of PC, the image is subset into four tiles and the results are mosaiced after extraction of roads.

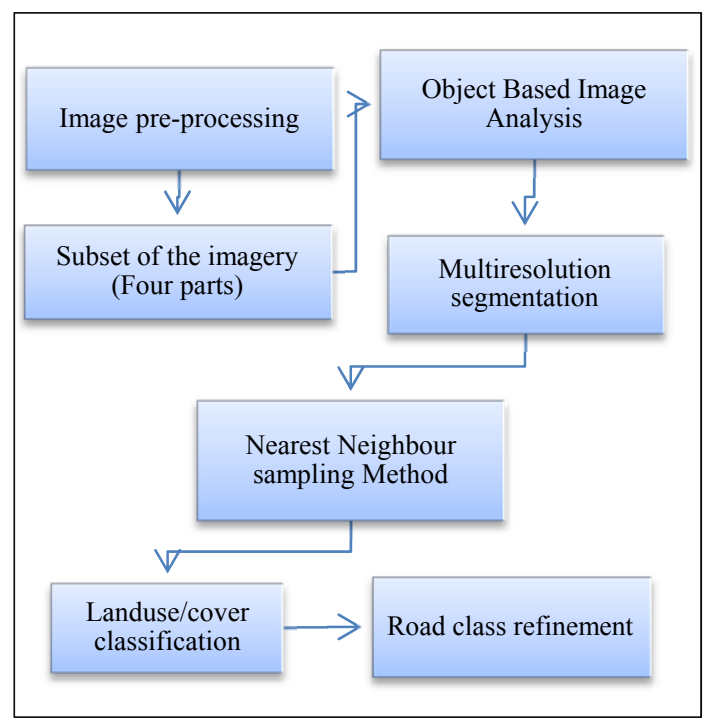

Figure 2. Flowchart of Nearest Neighbour Sampling method

Each part of the imagery has been segmented using multispectral layers. After proper segmentation, classification of the segmented objects has been done using nearest neighbour classification. In nearest neighbour technique, firstly, the classes are created and training samples are collected for each class. For 
classifying and obtaining best results Feature Space Optimization tool has been used which is provided by eCognition software. For land use/cover classification of the study area seven classes have been created and training samples have been collected. Nearest neighbour technique has been performed for classifying both the imageries. After classification refinement of classes has also been done. Both the classifications with different resolution imageries have provided different results. Detailed approaches have been explained in section 4.1 and 4.2 .

\subsection{Rule based OBIA classification}

The rule based OBIA classification technique have been carried out to overcome the issues related to NN sampling approach. In this method very high spatial resolution Kompsat imagery (2.8m MS and $0.7 \mathrm{~m}$ PAN) has been used. In this study, popularly used multi-resolution segmentation has been performed. However, for better segmentation results several additional algorithms have been applied for creating a layer which shows linear features like road. There are, three algorithms used for obtaining a line layer (Figure 3 ).

\subsubsection{Line Extraction}

The first algorithm used for creating line layer is line extraction. The line extraction algorithm creates a layer and classifies the pixels of the input layer according to their line filter signal strength (Definiens, 2012). The output layer using this algorithm has been extracted lines from the input high resolution panchromatic layer.

\subsubsection{Edge Extraction Lee Sigma}

Another algorithm has been applied for better line extraction results. This algorithm uses a specific edge filter that creates two individual layers from the original image. One layer represents bright edges and the other one dark edges (Definiens, 2012). Therefore, it is necessary to extract two layers one with bright and one with dark edges. Using Kompsat panchromatic $(0.7 \mathrm{~m})$ as input layer, the algorithm has been applied for extracting edge layer.

\subsubsection{Edge Extraction Canny}

Edge extraction Canny filter is used to enhance or extract feature boundaries (Definiens, 2012). The resulting layer shows high pixel values where there is a distinctive change of pixel values in the original image.

It was found that features in panchromatic layer are easily distinguishable than $2.8 \mathrm{~m}$ multispectral bands. Therefore, only panchromatic layer has been used for creating line layer.

The above three algorithms have been used for extracting a line layer for better extraction of road from the imagery. Each output layer has been used separately for obtaining better segmentation of objects. However, only the line layer created by applying the Edge Canny algorithm has given better segmentation results than the other two algorithms.

After segmenting the imageries, road extraction has been carried out using rule based classification routine in eCognition software. It was found that the line features in
$0.7 \mathrm{~m}$ panchromatic layer are easily distinguishable than $2.8 \mathrm{~m}$ multispectral bands. Therefore, the only panchromatic layer has been used for creating line layer. Further, these objects are classified into different classes using appropriate classification algorithm following refinement of classes.

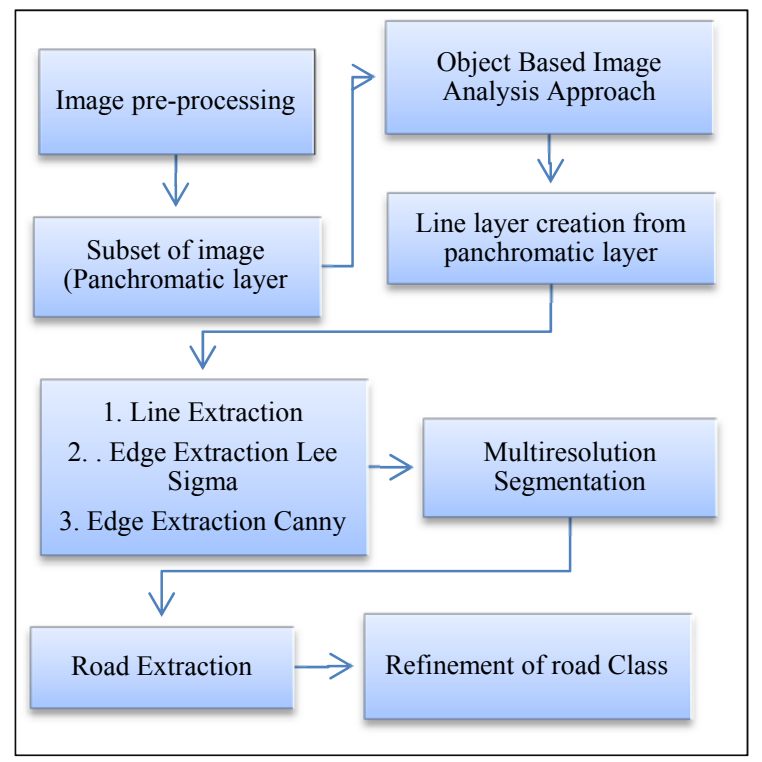

Figure 3. Flowchart of Rule based OBIA method

Three approaches (Table 1) have been used for extracting roads from high and very high resolution imagery. The approaches have been discussed in the following sections.

\begin{tabular}{|l|l|l|l|}
\hline $\begin{array}{c}\text { Road } \\
\text { Extraction } \\
\text { OBIA } \\
\text { Approach }\end{array}$ & Data Used & \multicolumn{1}{c|}{$\begin{array}{c}\text { Segmentation } \\
\text { Technique }\end{array}$} & $\begin{array}{c}\text { Classification } \\
\text { Technique }\end{array}$ \\
\hline $\begin{array}{l}\text { Nearest } \\
\text { Neighbour } \\
\text { Approach I }\end{array}$ & $\begin{array}{l}\text { IRS } \\
\text { Resourcesat-II } \\
(5.8 \mathrm{~m})\end{array}$ & $\begin{array}{l}\text { Multiresolution } \\
\text { segmentation }\end{array}$ & $\begin{array}{l}\text { Nearest } \\
\text { neighbour }\end{array}$ \\
\hline $\begin{array}{l}\text { Nearest } \\
\text { Neighbour } \\
\text { Approach II }\end{array}$ & $\begin{array}{l}\text { Kompsat 3 } \\
(2.8 \mathrm{~m} \text { MS and } \\
0.7 \mathrm{~m} \text { PAN) }\end{array}$ & $\begin{array}{l}\text { Multiresolution } \\
\text { segmentation }\end{array}$ & $\begin{array}{l}\text { Nearest } \\
\text { neighbour }\end{array}$ \\
\hline $\begin{array}{l}\text { Rule Based } \\
\text { Approach }\end{array}$ & $\begin{array}{l}\text { Kompsat 3 } \\
(2.8 \mathrm{~m} \text { MS and } \\
0.7 \mathrm{~m} \text { PAN) }\end{array}$ & $\begin{array}{l}\text { Multiresolution } \\
\text { segmentation }\end{array}$ & Rule based \\
\hline
\end{tabular}

Table 1. Road Extraction approaches for the study

\section{Road Extraction}

\subsection{Road Extraction using Nearest Neighbour OBIA Approach (I)}

The IRS Resourcesat-II (5.8m) imagery data has been used to extract road in this method. The methodology is shown in the Figure 1.

\subsubsection{Segmentation}

Precise segmentation is an essential aspect in objectoriented image classification. Meaningful image objects are created during segmentation process based on homogeneity and heterogeneity in color and shape. Multiresolution segmentation is a bottom up regionmerging approach which classifies pixels into objects 
subsequent segmentation steps thus constructing a semantic hierarchy, in order to finding desired single objects of interest (Baatz et al. 2004).

Multiresolution segmentation is the most commonly used segmentation technique used for segmenting the image pixels into objects (Baatz et al. 2004). All the parameters for segmentation have been selected through a trial and error method. Several combinations of the parameters (colour and shape) have been tested, and one optimum set of the parameters was selected based on visual inspection of the resultant image objects.

The scale parameter 10 (i.e. minimum 10 pixel in each segment) has been selected for optimum output (Figure 4).

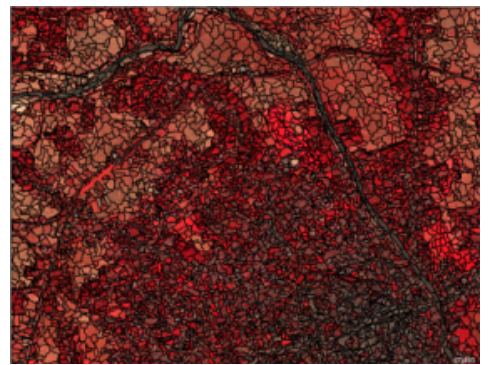

Figure 4. Multiresolution segmentation

\subsubsection{Classification}

After segmentation, nearest neighbour classification process has been carried out. Firstly, the training samples has been created for the classes such as agriculture, built up, fallow, sand bars, vegetation, swampy area, waterbody based on visual interpretation guided by Google Earth images. As mentioned in the methodology section 3.1 Feature space optimization is a data mining functionality which compares the features of the selected classes finding the combination of features producing largest average minimum distance between the training samples of different classes (Trimble 2011; Navalur 2007). The object statistics of the optimized feature space are calculated for the training samples and are used for classifying image objects on the basis of nearest neighbour samples (Nearest Neighbour classification). Same set of features is applied to all classes (Standard Nearest Neighbour). For obtaining best feature combination 20 features have been used. Out of which only five best features have selected for nearest neighbour classification through feature space optimization in eCognition software (Table 2). It is found that more number of parameters used, the longer the processing time required for data mining (Navalur, 2007). After classification the four parts of the imagery have been mosaiced for obtaining a seamless result for existing road mapping of the Titabor. From the mapping it has been found that many of the roads have been misclassified due to overlapping of some other class viz. roads have been mixed with building or other built up area and also with waterbody (Figure 5). In many parts the continuous road has been classified as fragmented parts.

Proper extraction of roads is necessary for further application and analysis. However, the extraction results from this approach are not very impressive for further usage. It is worth mentioning that $5.8 \mathrm{~m}$ spatial resolution is also not sufficient for road extraction. Due to mixture of many classes at this resolution misclassification is natural (Figure 6).

\begin{tabular}{|c|c|c|}
\hline Sl. No. & Selected Features & Optimized Features \\
\hline 1 & Mean Blue & Area \\
\hline 2 & Mean Green & Shape Index \\
\hline 3 & Mean Red & Mean NIR \\
\hline 4 & Mean NIR & Standard Deviation NIR \\
\hline 5 & Mean Maximum Difference & $\begin{array}{l}\text { Mean Maximum } \\
\text { Difference }\end{array}$ \\
\hline 6 & Mean Brightness & \\
\hline 7 & Standard Deviation Blue & \\
\hline 8 & Standard Deviation Green & \\
\hline 9 & Standard Deviation Reb & \\
\hline 10 & Standard Deviation NIR & \\
\hline 11 & Shape Index & \\
\hline 12 & Area & \\
\hline 13 & Roundness & \\
\hline 14 & Border Length & \\
\hline 15 & Length & \\
\hline 16 & Length/Width & \\
\hline 17 & Width & \\
\hline 18 & Asymmetry & \\
\hline 19 & Compactness & \\
\hline 20 & Border Index & \\
\hline
\end{tabular}

classification

\begin{tabular}{|l|l|l|l|}
\hline \multicolumn{1}{|c|}{ Purpose } & \multicolumn{1}{|c|}{ Algorithm } & \multicolumn{1}{c|}{$\begin{array}{c}\text { Threshold } \\
\text { Conditions }\end{array}$} & Layers used \\
\hline $\begin{array}{l}\text { Segmentation } \\
\text { of objects }\end{array}$ & $\begin{array}{l}\text { Multiresolution } \\
\text { Segmentation }\end{array}$ & $\begin{array}{l}\text { Scale } \\
\text { parameter: 5, } \\
10\end{array}$ & $\begin{array}{l}\text { Green (1), } \\
\text { Red(1), } \\
\text { NIR(1) }\end{array}$ \\
& $\begin{array}{l}\text { Shape : 0.3, 0.3 } \\
\text { Compactness: } \\
0.4,0.8\end{array}$ & \\
\hline $\begin{array}{l}\text { Road } \\
\text { extraction }\end{array}$ & $\begin{array}{l}\text { Nearest } \\
\text { Classification }\end{array}$ & - & $\begin{array}{l}\text { Segmented } \\
\text { Layer }\end{array}$ \\
\hline Refinement & Assign Class & & - \\
\hline
\end{tabular}

Table 3. Parameters for Nearest Neighbour OBIA

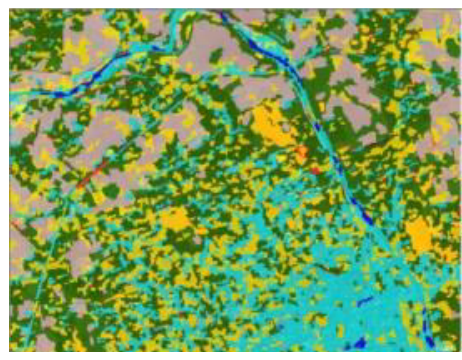

Figure 5. Classification of the image layer 


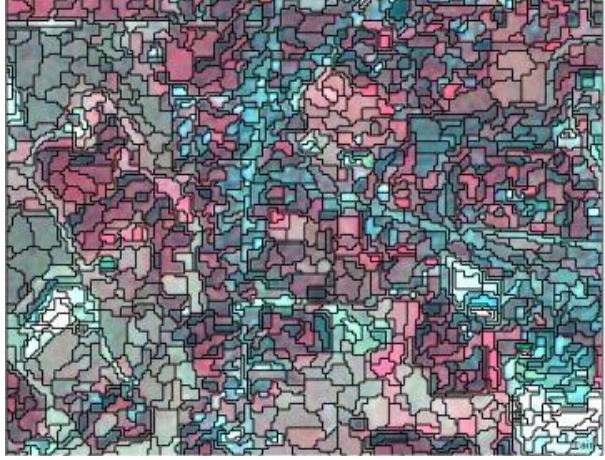

Figure 6. Segmented image

\subsection{Road Extraction using Nearest Neighbour OBIA Approach (II)}

In the previous section, the analysis has stated that high resolution imagery $(5.8 \mathrm{~m})$ has not provided better results using nearest neighbour technique. Therefore, this section has attempted to perform road extraction mapping on very high resolution imagery. As the very high resolution imagery is very expensive, therefore, small part of the district (Titabor) has been acquired for road mapping. The very high resolution satellite imagery Kompsat 3 (2.8m MS) has been used for the analysis. Again the imagery has been subset into small parts for classification purpose.

\subsubsection{Segmentation}

Multiresolution segmentation has been performed using different scale parameters. In the four parts the segmentation has been applied using the same scale parameter. Different scale parameters have been tested for properly segmenting the image objects. In lower scale parameter $(5,10$ and 15$)$ the objects have been oversegmented (Figure 7(a)) resulting misclassification of different classes. Therefore, higher scale parameters (40, 50,60 and 70) have been applied to obtain objects for classification. From all these scale parameters 40 and 50 can be used for multiresolution segmentation.
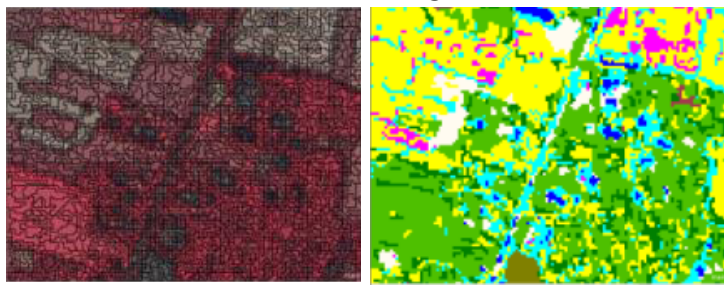

Figure 7. (a) Multiresolution Segmentation and (b) Classified layer

\subsubsection{Classification}

Same classification procedure has been used for classifying the segmented image objects (Figure 7(b)). Optimized features have been calculated using feature space optimization window as used for first NN classification (Table 2).

From the classification using nearest neighbour technique (Figure 8$)$ very high resolution imagery $(2.8 \mathrm{~m})$ is showing better results than high resolution imagery $(5.8 \mathrm{~m})$. However, in some parts the roads have been classified under other classes. In the rural areas where there is the mixture of land use/ cover classes such as agriculture, fallow land, unsurfaced roads, surfaced roads, semi-built up areas, vegetation, waterbody misclassification may occur. And the number of unsurfaced roads is more than the surfaced roads. Surfaced roads are different from unsurfaced roads in colour and tone. The surfaced roads can be classified better than the unsurfaced roads. The unsurfaced roads may not be classified properly due to their similarity to some other classes. For example, the unsurfaced roads have been classified under fallow land as there is similarity between them. Therefore, the road extraction from very high resolution imagery has provided not so satisfactory results.

\subsection{Road Extraction using Rule Based OBIA Approach}

As the both nearest neighbour OBIA techniques used for extracting the roads from high and very high resolution imagery in the previous sections have not provided better results, therefore, in this section rule based road extraction method has been applied using very high resolution Kompsat imagery. In this approach only panchromatic layer $(0.7 \mathrm{~m})$ has been used for segmentation to obtain road layer unlike previous approaches where multispectral layers have been used for segmentation. The MS layers $(2.8 \mathrm{~m})$ have been used only for classification and refinement of roads.

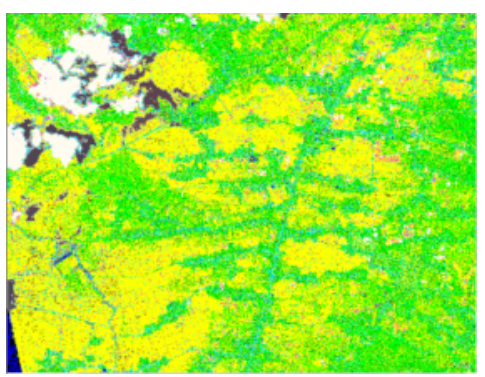

Figure 8. Classified image

\subsubsection{Segmentation}

Preprocessing before segmentation process has been discussed in the methodology (Section 3.2). Different scale parameters have been tried for obtaining the proper segmentation scale to segment the image objects. Higher the resolution of the imagery better and accurate would be the extraction of information. Roads are linear objects and therefore it is necessary to segment the image objects so that roads could be extracted properly. Both MS $(2.8 \mathrm{~m})$ and PAN $(0.7 \mathrm{~m})$ layer have been considered for line layer creation for extracting the roads accurately. However, apparently the higher resolution would provide better results. Therefore, PAN layer has been used for obtaining the line layer using three different algorithms for creating line layer (Table 4). The line layer obtained by using edge Canny algorithm (Figure 9) has been considered best among the three algorithm used for segmentation. After obtaining the best line layer, the multiresolution segmentation has been done using different scale parameters $(20,30,40,50,60$ and 70$)$ and shape and compactness for acquiring accurately 
segmented objects. The scale parameter for segmentation is 50 with shape 0.4 and compactness 0.5 has provided optimum segmentation result. The input layers used are panchromatic layer and line layer. The best segmentation result has been taken for further extraction of roads.

\subsubsection{Classification}

For classification of segmented objects rulesets have been created for extracting only the road features. The ruleset has been generated applying different algorithms and threshold values for extracting roads from the segmented objects (Table 4). Linear features can be extracted using spatial parameters such as Length, Length/Width, Length/Thickness, Width (Zou et al. 2016) etc. other than spectral parameters. In this rule based approach, after segmentation Length parameter has been used taking threshold values for extracting roads from the segmented objects. Many roads have been extracted properly using this parameter. Road class refinement has been done to obtain other roads which could not be extracted using the ruleset with Length parameter. Length/Width parameter has been used for extracting more roads. Though the roads have been extracted (Figure 11(a) and (b)) some areas which are not roads have been classified as roads. Therefore, to avoid this misclassification road class refinement has been done using the multispectral layers so that roads could be properly classified. For example, vegetation class has been misclassified as roads because of the tree coverage above the road. Therefore, to distinguish roads from the trees spectral parameter index NDVI has been used (Figure 13). From the Figure 10 and 12 , it can be observed that the roads are extracted accurately using different refinement rulesets.

The results of the rule based approach have provided better results than the nearest neighbour approach. The road extraction using spatial features (length and length/width) have properly extracted roads from the segmented objects. For accurate extraction more layers may be used for road refinement.

\begin{tabular}{|l|l|c|l|}
\hline \multicolumn{1}{|c|}{ Purpose } & \multicolumn{1}{|c|}{ Algorithm } & \multicolumn{1}{c|}{$\begin{array}{c}\text { Threshold } \\
\text { Conditions }\end{array}$} & Layers used \\
\hline $\begin{array}{l}\text { Pre-processing for } \\
\text { accurate road layer } \\
\text { extraction. } \\
\text { Creation of Linear } \\
\text { layer to be used in } \\
\text { segmentation }\end{array}$ & Line Extraction & - & $\begin{array}{l}\text { Panchromatic } \\
\text { layer }(0.70 \mathrm{~m})\end{array}$ \\
\hline -do- & $\begin{array}{l}\text { Edge Extraction } \\
\text { Lee Sigma }\end{array}$ & - & $\begin{array}{l}\text { Panchromatic } \\
\text { layer (0.70m) }\end{array}$ \\
\hline $\begin{array}{l}\text { Segmentation of } \\
\text { objects }\end{array}$ & $\begin{array}{l}\text { Eulge Canny } \\
\text { Segmentation }\end{array}$ & $\begin{array}{l}\text { Scale parameter: } \\
40 \\
\text { Shape : 0.3 } \\
\text { Compactness: 0.5 }\end{array}$ & $\begin{array}{l}\text { Line layer } \\
\text { created by } \\
\text { edge } \\
\text { extraction } \\
\text { Canny }\end{array}$ \\
\hline Road extraction & Assign Class & Length & $\begin{array}{l}\text { Segmented } \\
\text { Layer }\end{array}$ \\
\hline Refinement & Assign Class & Length/Width & $\begin{array}{l}\text { Classified } \\
\text { Layer }\end{array}$ \\
\hline $\begin{array}{l}\text { Refinement of road } \\
\text { class }\end{array}$ & Assign Class & NDVI, NDWI & Road layer \\
\hline
\end{tabular}

Table 4. Parameters Rule Based OBIA Approach
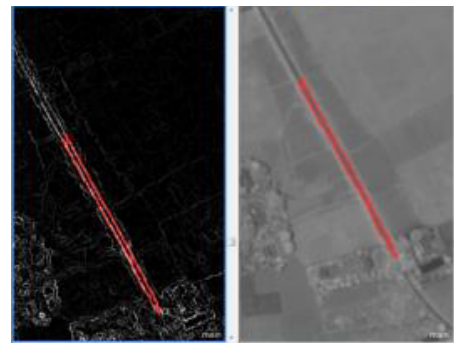

Figure 9. Segmentation using line layer created by edge extraction Canny

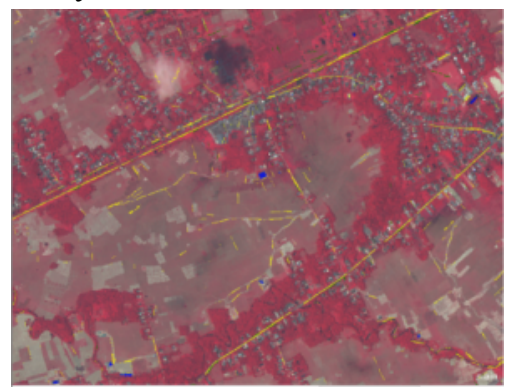

Figure 10. Classified image using rule based approach

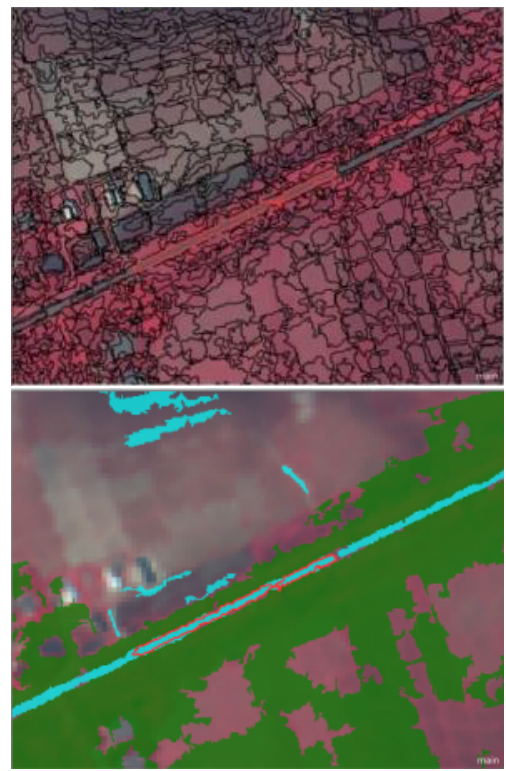

Figure 11. (a) Segmented image layer and (b) Classified Road layer

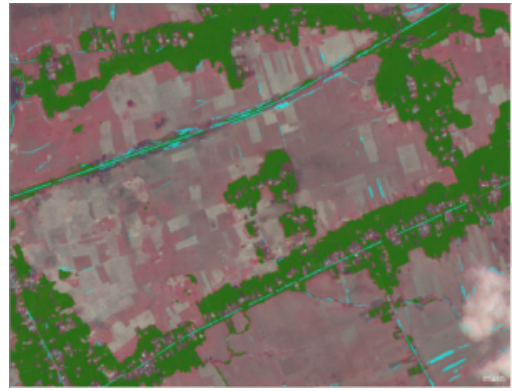

Figure 12. Road refinement using different rulesets

\subsection{Accuracy Assessment}

The accuracy assessment has been carried out by overlaying the extracted road layer with Open Street Map (OSM) road layer (www.openstreetmap.org) for the study area. There is a lateral shift of about $50 \mathrm{~m}$ in the satellite 
imagery extracted layer from the OSM roads may be attributed to the geo-referencing error. The section of roads available both in the OSM and the results of the three approaches (Table 1) have been selected for accuracy assessment. The first approach has shown low accuracy $(15 \%)$ as the roads have not been extracted properly from the imagery. The second approach has shown relatively better accuracy (25\%) than the first approach. The third approach which has shown 56\% accuracy may be used for road extraction. It has been found that $56 \%$ of the OSM roads are correctly classified through the third method. The lower accuracy may be due to the discontinuity of the roads extracted from the satellite imagery mostly covered by tree canopies on both side of the roads (Figure 13). As the study area is located in North East India the vegetation cover is more prominent in most of the areas. Therefore, continuity of roads could not be observed from the satellite imagery and particularly of the rural areas of Assam. This kind of discontinuity of roads can be solved by using manual cartographic post-processing. From the extraction of roads from the high resolution imagery road extraction it has been found that though three approaches have been used only rule based approach has shown better extraction results than the other approaches The main purpose of the study was to compare the road extraction results by various OBIA approaches which have been shown in the analysis. The results may be more accurate using very high resolution sub-meter level satellite imagery.

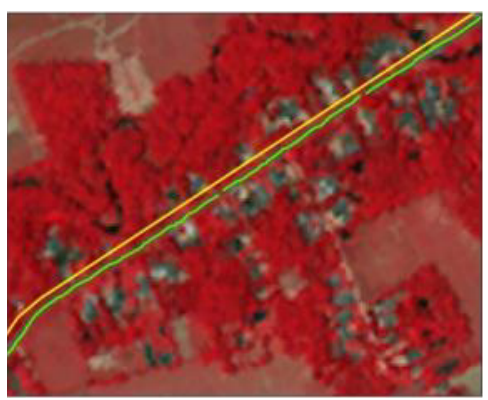

Figure 13. Overlay of Open Street Map and extracted road layer by third approach

\section{Discussion}

From the above results of road extraction using different OBIA methods, it has been found that accurate road extraction results can be obtained using very high resolution data. Three road extraction approaches have been applied to acquire accurate results. From the first approach of road extraction using nearest neighbour classification, it is found that the roads are misclassified in many parts and therefore, the results could not be used for further analysis of road modelling. The nearest neighbour approach using $5.8 \mathrm{~m}$ resolution imagery has highlighted the poor level of segmentation and classification. Due to lower resolution the roads could not be classified properly. Therefore, the imageries with spatial resolution less than $5 \mathrm{~m}$ may not be used for road extraction. For better extraction of roads very high resolution imagery $(2.8 \mathrm{~m})$ has been used in the second approach with nearest neighbour classification. The roads have also not been classified properly using the second approach. However, the second approach has given comparatively better results than the first approach. Using higher scale parameters for segmentation the better results can be obtained. Though many of the objects have been classified applying nearest neighbour sampling method in many parts roads have been classified under other classes. Class refinement using various rule sets such as spectral indices NDVI, NDWI and spatial parameters such as area, relation border to one class etc. has also not provided better results. It has been found that both the nearest neighbour approachs have not provided better results. Finally, the third approach which is rule based approach (Section 4.3) has been applied to extract roads. This approach using the very high resolution PAN and MS layers extracted the roads properly and more accurate results have been obtained. The segmentation based on the line layer created by Edge Extraction Canny has given best segmentation results for classifying the roads. The multiresolution segmentation has supported the further classification of roads. The rulesets for extracting the roads included both spectral (NDVI and NDWI) and geometrical parameters (Length, Length/Width etc.). The accuracy from this approach has shown better results $(56 \%)$ than the other two approaches. It can be stated that very high resolution panchromatic layer can be advantageous for extracting road features. However, multispectral layers can also be used for distinguishing roads from other features. It is found that the surfaced roads have been extracted accurately as they are distinct and separable from other linear features. For obtaining accurate extraction results the proper use of spectral as well as geometrical parameters can be beneficial. From the three approaches it has been observed that misclassification of roads occurred in the first approach. In the second approach the roads have been distinguished as surfaced and unsurfaced roads as very high resolution data has been used. However, the unsurfaced roads could not be extracted properly in the second approach. In the third approach, unsurfaced roads extraction has given better results using panchromatic layer. Therefore, for better and accurate road extraction results in case of rural areas the very high resolution imagery using rule based OBIA approach has been recommended.

\section{Concluding Remarks}

The rural road extraction using OBIA has been successful using the very high resolution imagery. The surfaced roads have been extracted accurately as compared to other unsurfaced roads. The rural area roads which include both surfaced and mostly unsurfaced roads are difficult to extract from the high resolution imagery. In the study area there are less surfaced roads as compared to unsurfaced roads. From the OBIA analysis it has been found out that the road extraction has been carried out better in very high resolution imagery using rule based approach. For feature extraction very high resolution imagery (Above $2.8 \mathrm{~m}$ ) has been proved more useful as 
objects can be extracted accurately. The road extraction in rural areas is a challenging task as there is difficulty in extracting unsurfaced roads. Starting from high resolution and nearest neighbour approach and moving to very high resolution and rule based approach has provided a detailed road extraction methodology using different resolution imageries and also different approaches. This methodology also shows the applicability of different road extraction approaches specifically for rural areas. The present rule based approach with very high resolution panchromatic layers can be further used for extracting roads in other rural areas.

\section{References}

Baatz, M., Benz, U., Dehghani, S., Heynen, M., Höltje, A., Hofmann, P., Lingenfelder, I., Mimler, M., Sohlbach, M., Weber, M. and Willhauck, G. (2004). eCognition Professional: User guide 4. (Munich: Definiens-Imaging)

Blaschke, T. (2010). Object-based image analysis for remote sensing. ISPRS International Journal of Photogrammetry and Remote Sensing, 65 (1): 2-16

Blaschke, T., G. J. Hay, M. Kelly, S. Lang, P. Hofmann, E. Addink, R.Q. Feitosa, F.M.H.,Werff, Frieke van Coillie and D. Tiede. (2014). Geographic Object-Based Image Analysis - Towards a new paradigm, ISPRS Journal of Photogrammetry and Remote Sensing, 87: 180-191

Benz, U.C., Hofmann, P., Willhauck, G., Lingenfelder, I., Heynen, M. (2004). Multiresolution, object-oriented fuzzy analysis of remote sensing data for GIS-ready information. ISPRS Journal of Photogrammetry and Remote Sensing, 58 (3-4), 239-258.

Bong, D. B. L., C. Laik and A. Joseph. (2009). Automatic road network recognition and extraction for urban planning, World Academy of Science, Engineering and Technology, 53: 209-215.

Definiens. (2012). Reference Book. Definiens Documentation, München, Germany

Duong, N. D. (2012). Water body extraction from multi spectral image special pattern analysis, International Archives of Photogrammetry Remote Sensing and Spatial Information Sciences, 39(8): 181-186

Fukubayashi Y. and Makoto K. (2014). Improvement of rural access roads in developing countries with initiative for self-reliance of communities, Soils and Foundations, 54(1):23-35

Hay, G.J., Blaschke, T., Marceau, D.J. and Bouchard, A. (2003). A comparison of three image-object methods for the multiscale analysis of landscape structure. ISPRS Journal of Photogrammetry and Remote Sensing, 57: 327-345.

Hay, G.J. and Castilla, G. (2008). Geographic ObjectBased Image Analysis (GEOBIA): A new name for a new discipline. In: Blaschke, T., Lang, S., Hay, G. (Eds.), Object Based Image Analysis. Springer, Heidelberg, Berlin, New York, pp. 93-112.

Lang, S., Schöpfer, E., Langanke, T., 2008. Combined object-based classification and manual interpretation-
Synergies for a quantitative assessment of parcels and biotopes. Geocarto International, 23 (4), 1-16.

Liu H., J. Li and M.A. Chapman. (2003). Automated Road Extraction from Satellite Imagery Using Hybrid Genetic Algorithms and Cluster Analysis, Journal of Environmental Informatics, 1(2): 40-47.

Luo J.C., Sheng Y.W., Shen Z.F. and Li J. L. (2010). High-precise Water Extraction Based on Spectralspatial Coupled Remote Sensing Information, Proc. 2010 IGARSS: 2840-2843

Mangala, T.R. and Bhirud, S.G. (2010). An Effective ANN-Based Classification System for Rural Road Extraction in Satellite Imagery, European Journal of Scientific Research, 47(4): 574-585

Ministry of Rural Development (MoRD). (2005) Pradhan Mantri Gram SaadakYojna Operations Manual. National Rural Road Development Agency

Movaghati, S., Moghaddamjoo, A., Tavakoli, A. (2010). Road Extraction from Satellite Images Using Particle Filtering and Extended Kalman Filtering, IEEE Transactions on Geo Science and Remote Sensing, 48(7):2807-2817

Navalur, K. (2007). Multispectral Image Analysis using the Object-Oriented Paradigm. CRC Press, Taylor \& Francis Group

Quackenbush L. J. (2004). A review of techniques for extracting linear features from imagery, Photogrammetric Engineer and Remote Sensing, 70(12): 1383-1392.

Rao P.J. (2000). Maintenance of Rural Roads Problems and Prospects. (Retrieved from http://pmgsy.nic.in/pmg9103.asp)

Shi,W.Z., Z.L. Miao and J. Debayle. (2014). An integrated method for urban main-road centerline extraction form optical remotely sensed imagery, IEEE Transactions on Geoscience and Remote Sensing, 52 (6): 3359-3372

li J. and Zhang, Q. (2000). Applicability of a gradient profile algorithm for road network extraction, Canadian Journal of Remote Sensing, 26(5): 428-439.

Wang J. and Zhang, Q. 2000. Applicability of a gradient profile algorithm for road network extraction, Canadian Journal of Remote Sensing, 26(5): 428-439.

Wang, Y., Y. Tian, X. Tai and L. Shu (2006). Extraction of main urban roads from high resolution satellite images by machine learning. Proceedings of the Asian Conference on Computer Vision, Volume 1, January 14, 2006, Springer Berlin/Heidelberg, pp: 236-245.

Zou, X., Zhao G., Li J.,Yang Y. and Fang Y. (2016). Object based image analysis combining high spatial resolution imagery and laser point clouds for urban land cover. The International Archives of the Photogrammetry, Remote Sensing and Spatial Information Sciences, Volume XLI-B3, 2016 XXIII ISPRS Congress, 12-19 July 2016, Prague, Czech Republic 